\title{
Large Eddy Simulation of Flows near a Groin in a Straight Open Channel
}

\author{
W. L. Wei ${ }^{1 *}$, J. S. Wang ${ }^{2}$, H. C. Dai ${ }^{3}$ \\ ${ }^{1}$ Institute of Water Conservancy and Hydraulic Engineering, Xi'an University of Technology, Xi'an \\ 710048, China \\ ${ }^{2}$ College of Automation, Northwestern Polytechnical University, Xi'an 710072, China \\ ${ }^{3}$ Institute of Water Conservancy and Hydraulic Engineering Hohai University, Nanjing 210024, China \\ Email: liuyuling@xaut.edu.cn
}

\begin{abstract}
Large eddy simulation along with a physical fractional-step method was applied to simulate flows near a groin in a straight open channel. The basic idea of this physical fractional-step method is that according to the behavior of each differential operator, the governing equations can be separated into three parts. The first step is a convective problem, which can be solved by the central-upwind deference scheme; the second is a diffusive problem, solved by the central deference scheme; and the third is a source term (pressure equation), solved by the SOR iteration method. The flow phenomenon and characteristics simulated by the proposed method agree well with the experimental data. The research shows that the LES model cooperated with the physical fractional-step method has powerful capacity in the simulation of microstructures of turbulent flows, and can be widely applied to the solution of real engineering problems.
\end{abstract}

\section{REFERENCES}

1. Smagorinsky J S. General circulation experiments with the primitive equations. The Basic Experiment, 1963; 91: 99-164

2. Deardorff $\mathbf{J}$ W. A numerical study of three-dimensional turbulent channel flow at large Reynolds numbers. Journal of Fluid Mechanics, 1970; 41: 453-480

3. Bardina J, Ferziger J H, Reynolds W C.Improved subgrid models for large eddy simulation, AIAA Paper, 1980; 80: 1357

4. Moin P. Numerical investigation of turbulent channel flow. Journal of Fluid Mechanics, 1982; 118: 341-377

5. Germano M, Piomelli U, Cabot W. A dynamic subgrid scale eddy viscosity model. Physics of Fluid, 1991; A3: 1760-1765

6. Ghosal S, Lund T S, Moin P. A dynamic location model for large eddy simulation of turbulent Flows. J Fluid Mech, 1995; 286: 229-255

7. Wei W L. Theory of Computational Hydraulies and Its Application, Xian: Shanxi Science and Technology Press, 2002, 100-140

8. Rajaratnam N, Nwachukwu B. Turnulence of open channel flow over smooth and rough beds. Proc $J S C E, 1975 ; 241: 115-168$ 